
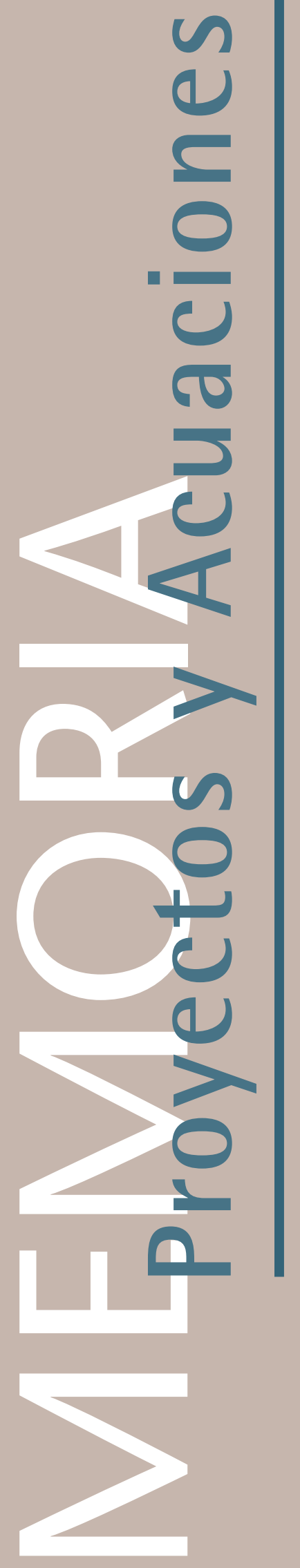

\title{
Casulla del terno blanco del Rey Fernando el Católico Investigación y Tratamiento
}




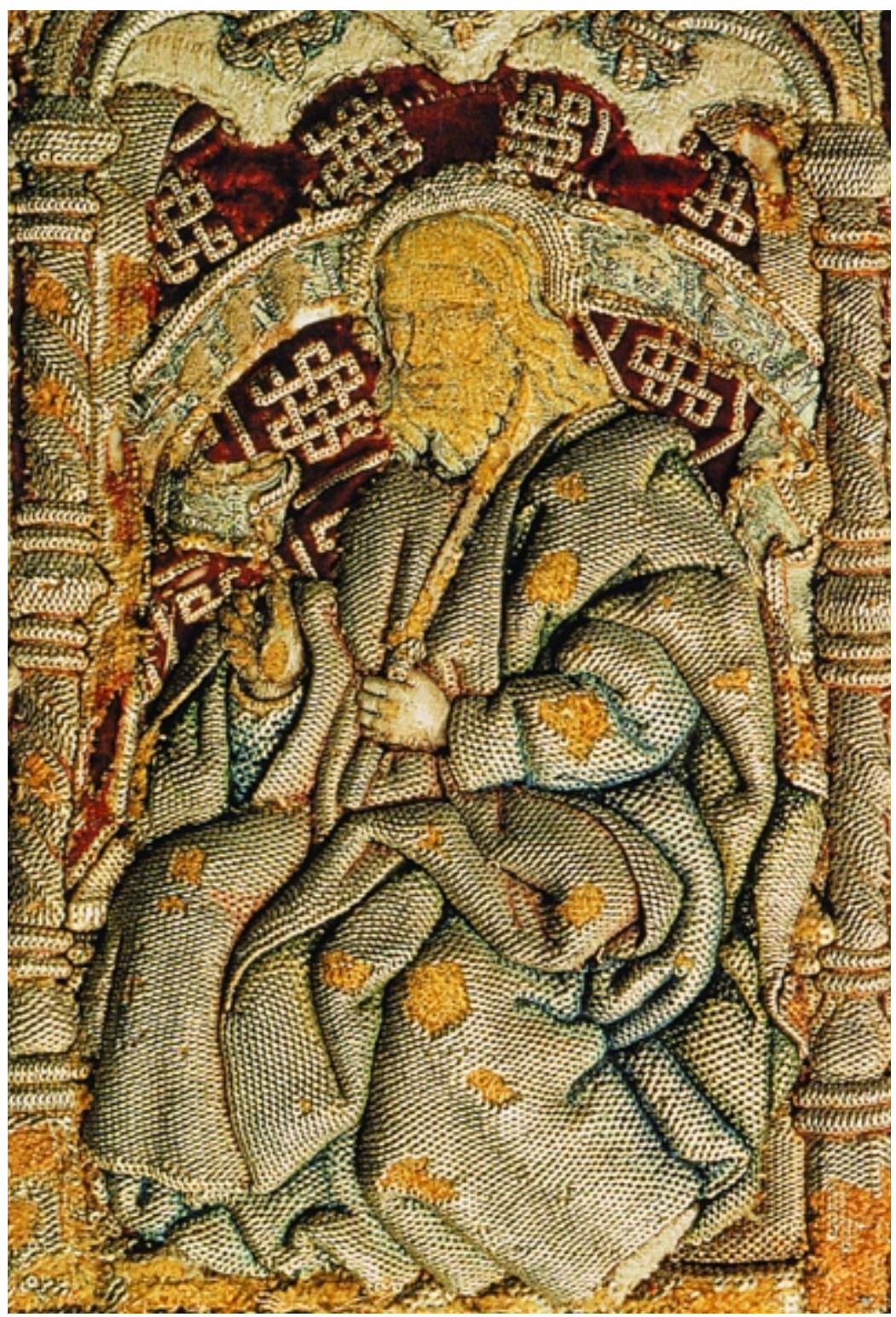

I. Encasamento del orfre decorado con arco conopial e imaginería.

\section{Estudio Histórico-Artístico}

Por Real Cédula dada en Medina del Campo el día 13 de septiembre de 1504, doce años después de la conquista de Granada, los Reyes Católicos decidieron la fundación de su propia capilla sepulcral en dicha ciudad. La enriquecieron con una magnífica colección de pintura flamenca, italiana e hispano-flamenca, ricos objetos de platería y suntuosos ornamentos bordados, que junto a numerosos enseres personales, constituyen un patrimonio de gran valor histórico-artístico. Manuel Gómez Moreno nos describe (1874) que entre los objetos litúrgicos donados por el rey a la Capilla Real granadina, se encontraban cinco ternos, de los que en la actualidad sólo se conserva parte del conocido como terno blanco "chapado" del rey Fernando el Católico. Eisman Lasaga (1989) encuentra que este conjunto de tejidos es citado por primera vez en 1536 ,
La intervención de la casulla del terno blanco chapado del Rey Fernando el Católico se enmarca dentro de las actividades del Proyecto de Investigación, Intervención y Acondicionamiento Museográfico que dirige y coordina el Instituto Andaluz del Patrimonio Histórico (IAPH). Esta intervención, pionera en el territorio andaluz, tiene como objetivo establecer una metodología de estudio y actuación dentro de la conservación-restauración del Patrimonio Textil de nuestra región, similar a la que se viene aplicando para otros bienes culturales.

en el Libro de Visitación del Archivo de la Capilla Real, bajo la denominación "brocado carmesí pelo de armas sembrados"; esta misma autora realiza una primera descripción de la casulla objeto del presente estudio.

En el Libro de Visitación antes citado, se hace referencia a los diferentes componentes de este terno: casulla, capa pluvial, dos dalmáticas con sus respectivos collares, frontal de altar, varias estolas, manípulos, amitos y albas. En los sucesivos inventarios posteriores, que se conservan en el Archivo de la Capilla Real (1572, 1655, 1657, I78।, 1787, 1794, I800, I827. 1859 y 1870 , entre otros), se constata la desaparición, en parte consecuencia del uso y en parte posiblemente debido a transformaciones o a expolio, de un gran número de tales piezas. Así, en los inventarios de 1794 (Leg.58, pág.6) y 1800 (Leg. 58, pág. 7) se hace referencia a capa pluvial, casulla, dalmáticas y 


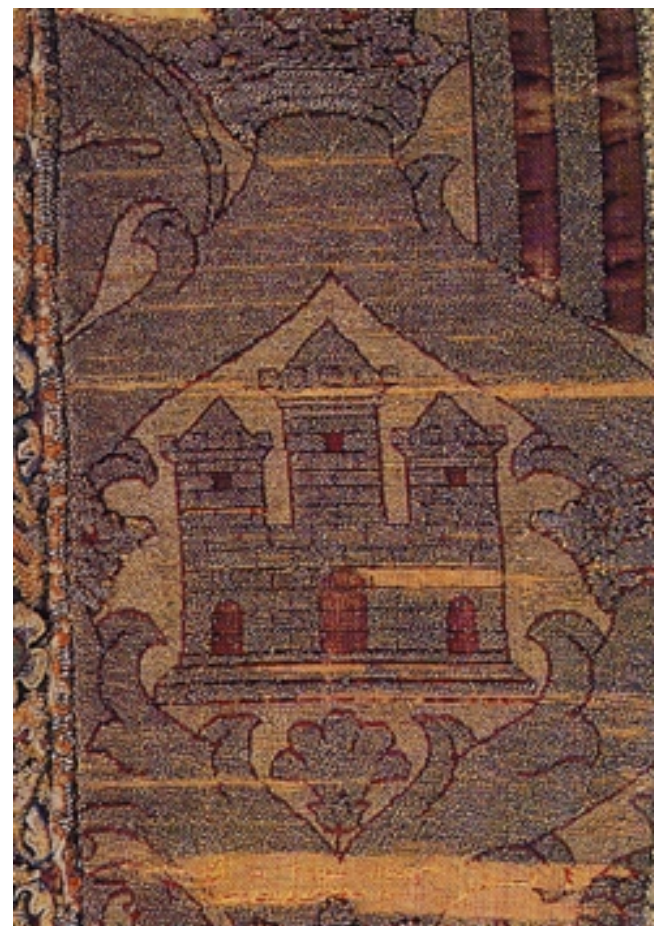

collares, todo bordado con lentejuelas de plata, pero ya no se citan manípulos ni estolas. En el de 1870 sólo aparece registrada la existencia de la casulla y de dos dalmáticas, una sin su collar. Lo recogido en este último inventario es lo único que se conserva en Granada en la actualidad. La capa pluvial está expuesta en el Museo Histórico de Tejidos de la ciudad francesa de Lyon, que según figura en los fondos documentales del propio museo, la adquirió en subasta pública celebrada en París el día 16 de junio de 1893 , junto con otras quince piezas de tejido, todas procedentes de la colección Spitzer, siendo la capa la de mayor precio de la venta.

La casulla del terno blanco chapado existente en la Capilla Real de Granada se compone de cuatro partes: cuerpo o soporte, orfre o cenefa central, galón y forro.

El cuerpo está confeccionado de un tejido cuya técnica es de terciopelo, alternando fondos lisos, bucles de hilos dorados y pelos de seda carmesí; su decoración está constituida por rombos formados por gruesos tallos con brotes de vegetación engarzados por coronas, en cuyo interior se alternan los distintos emblemas heráldicos de los monarcas (león rampante y coronado del reino de León, castillo con tres torres y almenado de Castilla, barras de Aragón, águila de Sicilia y la granada, símbolo de la ciudad conquistada).

El orfre, que recorre verticalmente la casulla, es de terciopelo rojo, bordado en realce de imaginería con hilo de oro, sedas matizadas y chapas horadadas, en cuya aleación aparecen distintos metales (oro, plata y cobre ), dispuesta en forma de escamas, siendo a éste
2. Detalle del cuerpo, decorado por rombos en cuyo interior aparecen los emblemas heráldicos de los Reyes Católicos.

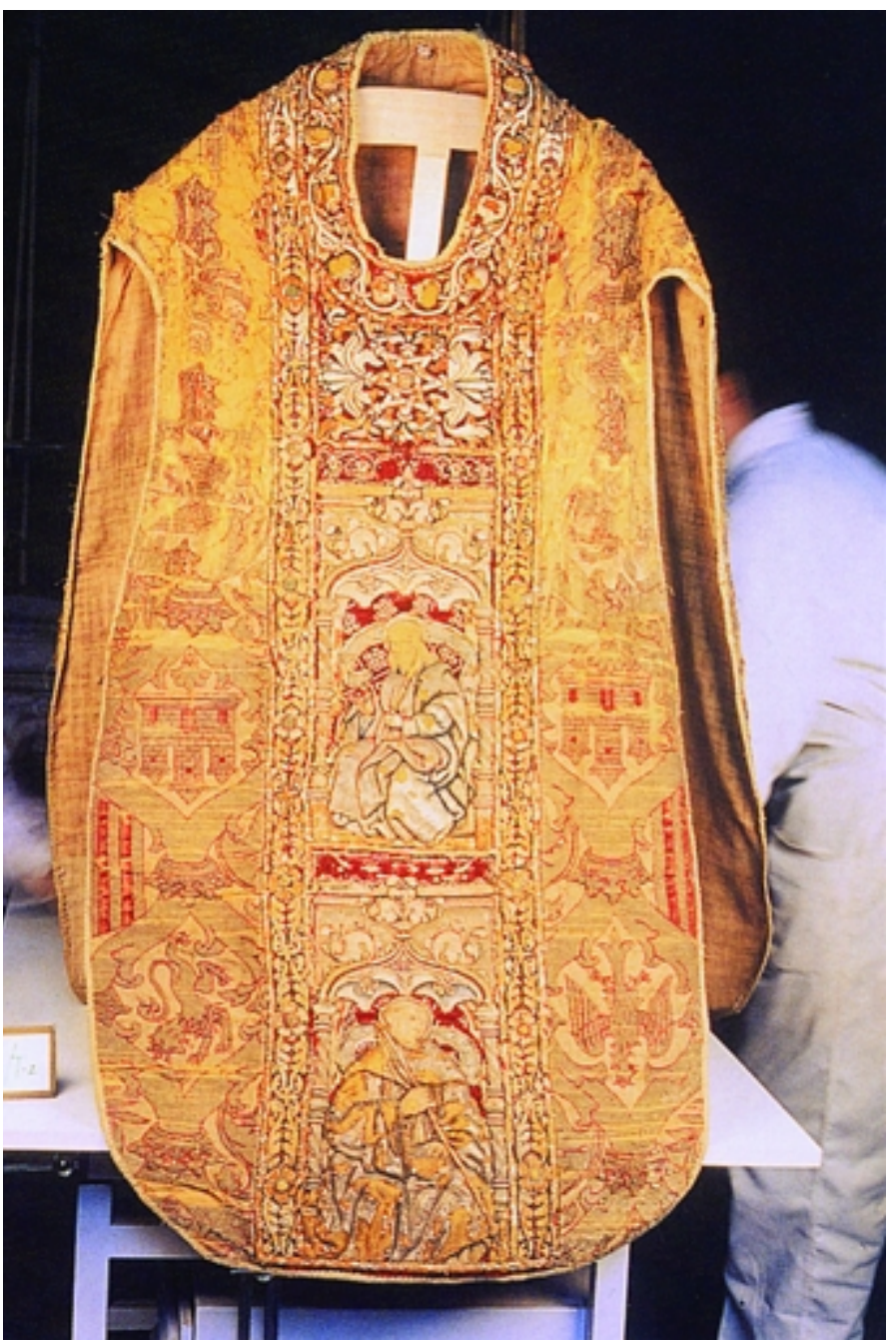

último adorno al que alude la denominación, terno chapado, por la que se conoce el conjunto de la obra. Tanto en la parte anterior como en la posterior, aparece estructurado por tres encasamentos separados entre sí por pequeños zócalos, a los que están cosidas lentejuelas formando dibujos geométricos y florales. En el interior de cada encasamento existe una estructura arquitectónica en forma de capilleta de estilo gótico, excepto en el superior de la parte anterior que es el más pequeño, y está decorado por una estrella, centrada y entrelazada, de ocho puntas de las que salen motivos vegetales. Los restantes encasamentos están decorados por imaginería y arcos conopiales apoyados en columnas anilladas y entorchadas con altos basamentos, todo ello en realce. La iconografía hace referencia a santos de cuerpo entero, sedentes y nimbados, que tienen a la altura de la cabeza filacterias 


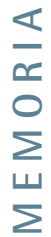

I. GROS DE TOURS: Ligamento derivado del tafetán con la particularidad de que por cada hilo de urdimbre pasan dos de trama. Nombre general del acanalado horizontal de dos pasadas de trama.

2. TRAMA DE LANZADO: Trama suplementaria que pasa por todo el ancho de la tela.

3. TRAMA ESPOLINADA:

Trama utilizada para efectos de decoración insertada con espolines, nombre que reciben las pequeñas lanzaderas usadas por el tisaje de este tipo de tramas. onduladas; en éstas quedan algunas letras, o parte de ellas, formadas por chapas metálicas, pudiéndose leer aún en la actualidad, aunque con cierta dificultad, versículos en latín del Símbolo Apostólico. En los tres encasamentos de la parte posterior y en el central de la anterior, aparecen figuras que, atendiendo a criterios iconográficos, es decir considerando las leyendas y los atributos que portan, presumiblemente representan Apóstoles. La única excepción es el encasamento inferior de la parte anterior: aparece un personaje con hábito franciscano, tonsura clerical, libro en la mano izquierda y bandera plegada en la derecha; en su filacteria, que se lee con menos dificultad que las restantes, aparece RESURRECTIONEM CARNIS. Los lados del orfre están delimitados por retorcha ornamentada con flores de cinco pétalos y hojas carnosas encontradas; la simetría de estos dibujos puede interpretarse como un anuncio de la llegada del Renacimiento.

En torno al orificio central, como parte independiente pero unida al orfre, existe un ancho galón bordado en relieve, con motivos de plantas y frutas que dibujan una especie de tallo serpenteante con pequeñas hojas, anillas y granadas, dispuestas armónicamente.

En el Archivo de la Curia de Granada, existe un documento fechado en 1604 (Leg. I 18, pág. I 3), referente a un proyecto de restauración de los ternos propiedad de la Capilla Real, según el cual los bordadores Alonso Núñez de Villarroel y Juan de Villalón, ambos de Granada, valoran en mil ducados el arreglo de "un terno de brocado carmesí que dio el rey de Aragón con las guarniciones de chapería de plata y oro, el cual estaba muy estragado (estropeado)". Creemos que el terno citado, objeto de aquella posible restauración, debe ser el que nos ocupa.

Parece evidente que a lo largo de su historia, esta pieza ha sufrido diversas intervenciones, algunas de las cuales han debido modificar su forma original. En la época en que es realizada, las casullas tenían forma casi circular (tipo planeta); prueba de ello son la casulla del terno de cardenal Mendoza, que se conserva en la catedral de Toledo, y numerosas representaciones pictóricas que así lo atestiguan. Pero en los siglos posteriores hay una tendencia a reducir las dimensiones de esta vestimenta litúrgica, para mayor comodidad del oficiante. En su forma actual, la casulla del terno chapado carece de caídas laterales; y, además, durante los trabajos de restauración, apareció un trozo del mismo tejido del que está hecho el cuerpo, guardado bajo el forro.

El origen de la casulla debe situarse en los últimos años del siglo XV y primer tercio del XVI. Históricamente es una donación del rey Fernando el Católico. La técnica de realización del tejido del cuerpo es similar a la utilizada para la fabricación de los tejidos usados en los ternos de los cardenales Mendoza (+ 1495) y Cisneros (1517) que se conservan en la catedral toledana, y los rojos son fibras teñidas con kermes, tintura utilizada desde la antigüedad. Sin embargo, los análisis químicos ahora realizados, han revelado que el teñido en rojo de las fibras de terciopelo del orfre fue realizado con la sustancia denominada cochinilla americana, tinte que no se comercializa en Europa hasta bien entrado el siglo XVI. Asimismo, aunque estilísticamente la decoración principal del orfre es claramente encuadrable en el gótico tardío, en la retorcha se incorporan motivos renacentistas propios del grutesco. Parece evidente que el orfre de la casulla podría ser resultado de un enriquecimiento de los elementos del terno, posterior a su donación por el rey Católico. Obras de este excepcional valor artístico ponen de manifiesto el gran impulso dado en esa época a la industria textil y al arte del bordado en toda Europa.

\section{Referencias Bibliográficas}

- Eisman Lasaga, C., 1989. El arte del bordado en Granada (siglos XVI al XVIII). Granada.

- Gómez Moreno, M., I874. "Apuntes que pueden servir de historia del bordado de imaginería en Granada". Rev. El liceo de Granada. Imp. Ventura Sabatel, Granada.

\section{Datos técnicos de la obra}

Las características técnicas de los tejidos y riqueza de la ornamentación de las piezas principales de la casulla -cuerpo y orfre- hacen que esta obra sea única en su género y una de las pocas conservadas hasta nuestros días. Por ello consideramos de interés dedicar un apartado específico a los aspectos técnicos y datos constructivos de la misma.

Tras el atento examen de la obra en el taller de tejidos del IAPH mediante inspección visual y en algunos casos ayudados de instrumentos de aumento, como es la lupa binocular, se ha podido determinar la descripción técnica de los tejidos y de la ornamentación empleada en su realización, como veremos a continuación:

Cuerpo: Constituido por dos laterales unidos al orfre para configurar la morfología de la casulla. El tipo de tejido utilizado en su construcción es conocido técnicamente bajo la denominación de terciopelo labrado de un cuerpo sobre fondo "Gros de Tours"I (gráfico n I I). La materia base es la seda de color amarillo en la trama, y de colores amarillo y rojo en la urdimbre; esta última tonalidad es empleada para configurar el terciopelo de la decoración. Todo el tejido está a su vez cubierto por una "trama de lanzado"2 de hilos metálicos enrollado en un alma de seda, también de color amarillo, que crea el efecto de bucle o de hilo llano, tanto en el fondo como en los emblemas heráldicos, mientras que en la corona, se emplea para obtener el mismo efecto, un hilo metálico de mayor grosor que el anterior y una trama diferente denominada "espolinada"3. La complejidad de la propia construcción del tejido configura su decoración, sin necesidad de ningún tipo de elementos complementarios superpuestos.

Orfre o cenefa de decoración central: Esta pieza está constituida por una retorcha ${ }^{4}$ y por un galón que circunda el cuello. Su construcción corresponde a la técnica de bordado en relieve o realce aplicado sobre un 


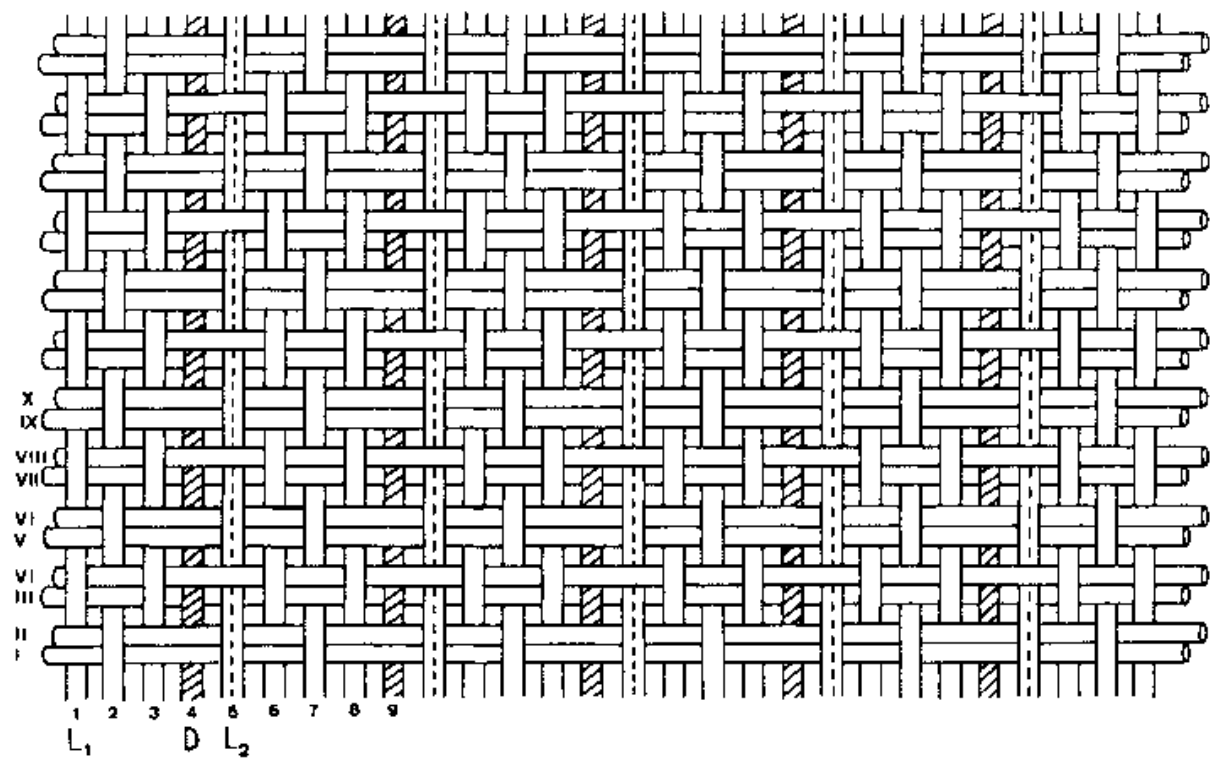

Tabla $n^{\circ}$ | Descripción técnica de la Casulla

\begin{tabular}{|c|c|c|c|}
\hline & CUERPO & ORFRE & FORRO \\
\hline DIMENSIONES & $\begin{array}{l}\text { Anverso: } 146 \times 069 \mathrm{~cm} \\
\text { Reverso: } 146 \times 089 \mathrm{~cm}\end{array}$ & $\begin{array}{l}\text { Anverso: } 111 \text { x } 031 \mathrm{~cm} \\
\text { Reverso: } 146 \times 031 \mathrm{~cm}\end{array}$ & $\begin{array}{l}\text { Anverso: } 143 \times 066 \mathrm{~cm} \\
\text { Reverso: } 143 \times 086 \mathrm{~cm}\end{array}$ \\
\hline $\begin{array}{l}\text { CALIFICACIÓN TÉCNICA } \\
\text { DE LOS TEJIDOS }\end{array}$ & $\begin{array}{l}\text { Terciopelo labrado de un cuerpo sobre } \\
\text { fondo "Gros de Tours" y trama de lanzado } \\
\text { y espolinado metálica }\end{array}$ & $\begin{array}{l}\text { Terciopelo simple de un cuerpo, } \\
\text { con refuerzo posterior de tejido de tafetán }\end{array}$ & Tafetán \\
\hline TIPO DE FIBRAS & $\begin{array}{l}\text { Seda e hilos } \\
\text { metálicos }\end{array}$ & $\begin{array}{l}\text { Numerosos estratos } \\
\text { de seda, lana y linos }\end{array}$ & Algodón \\
\hline $\begin{array}{l}\text { TIPO DE } \\
\text { ORNAMENTACIÓN }\end{array}$ & $\begin{array}{l}\text { Terciopelo, hilos metálico } \\
\text { buclados y llanos }\end{array}$ & $\begin{array}{l}\text { Bordados en realce aplicados sobre una } \\
\text { base de terciopelo simple }\end{array}$ & No presenta \\
\hline $\begin{array}{l}\text { MATERIA Y TÉCNICA DE } \\
\text { LA ORNAMENTACIÓN }\end{array}$ & $\begin{array}{l}\text { Seda e hilo metálico } \\
\text { tejido en telar manual }\end{array}$ & $\begin{array}{l}\text { Base de pergamino. Relleno } \\
\text { Lentejuelas y sedas matizadas }\end{array}$ & No presenta \\
\hline
\end{tabular}

fondo de terciopelo simple de un cuerpo ${ }^{5}$ de color rojo de seda sobre el cual se desarrolla una amplia gama de técnicas de ornamentación.

La forma plástica de la decoración se obtiene por relleno de diversos materiales estratificados. En los personajes sólo se ha podido identificar el estrato más superficial por ser el único que nos facilitó la posibilidad de tomar una pequeña muestra, tratándose de lana de color amarillo, mientras que en los restantes motivos ornamentales sí se ha podido determinar la secuencia de estratos, encontrándonos seda de color morado, lana de color amarillo y lino de color crudo por este orden. Los personajes y encasamentos se encuentran aplicados sobre una base de pergamino muy duro que hace las veces de patrón.

La decoración con lentejuelas se realiza sobre el estrato más superficial de lana, fijándolas una a una al soporte de base con hilos de seda amarillos y dispuestas con técnica de escama de pez. Se han detectado 14 tipos diferentes que varían en tamaño y forma.

El colorido final es obtenido, bien mediante la matización de las lentejuelas con hilos de seda de diversos colores para configurar las vestiduras y los motivos ornamentales, o bien, como en el caso de las carnacio- nes, directamente en seda con punto de matiz sobre el tejido de lana a fin de obtener el efecto denominado "pintado a la aguja".

Con objeto de dar protección a toda la composición y ayudar a soportar también el peso de los bordados toda la superficie del orfre está fijado sobre un tejido de tafetán de base6.

\section{Unión de las diferentes piezas constitutivas}

Los cuerpos realizados en ocho piezas diferentes y el forro se unen al orfre mediante costura simple realizada manualmente con punto de pespunte siguiendo siempre una sola dirección y empleando para ello un hilo de algodón muy grueso, de un color ocre claro del mismo tono que el forro.

A continuación, el forro se une al resto de la composición mediante dos costuras de fijación llevadas a cabo a tres $\mathrm{cm}$. del borde del orfre, realizadas también con punto de pespunte y empleando para ello hilo de algodón muy grueso de color ocre claro.

Por último la fijación del galón que circunda todo el borde de la casulla y mantiene unidas a todas las piezas, se realiza mediante un punto de remate que apro-
Gráfico I. Construcción interna del tejido: tipo de ligamento "Gros de Tours".

Li: Urdimbre ligamento base

D: Urdimbre pelo roja

L2: Urdimbre ligamento hilo metálico amarilla 


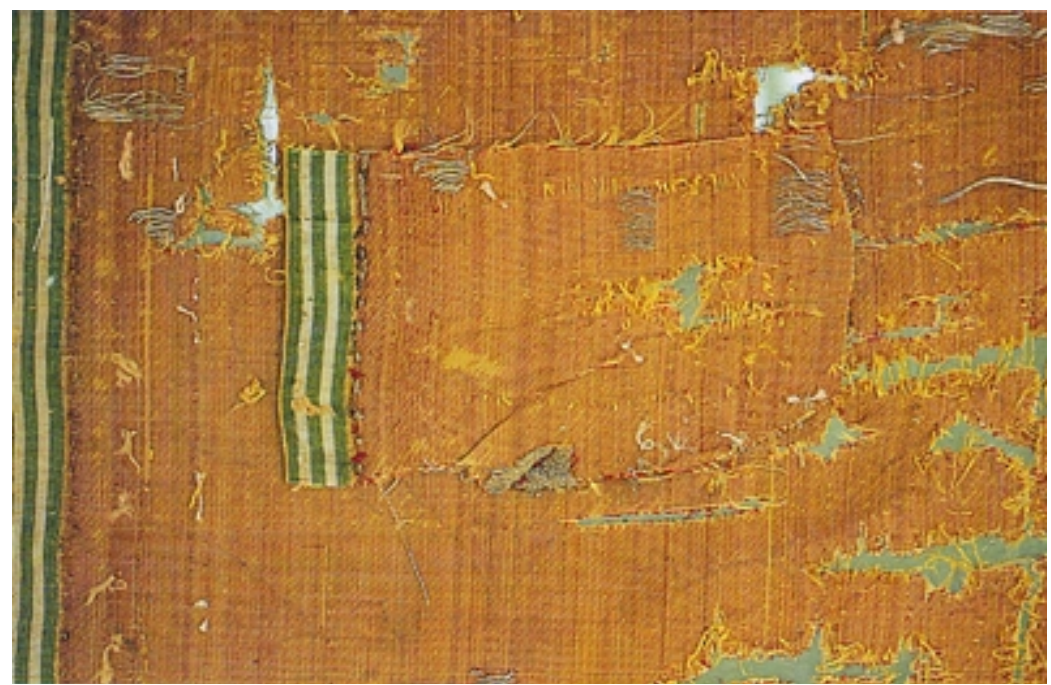

3. Detalle del interior del cuerpo izquierdo donde se aprecia un parche recortado de la propia pieza.

4. Vista general del reverso de la casulla antes de la intervención.

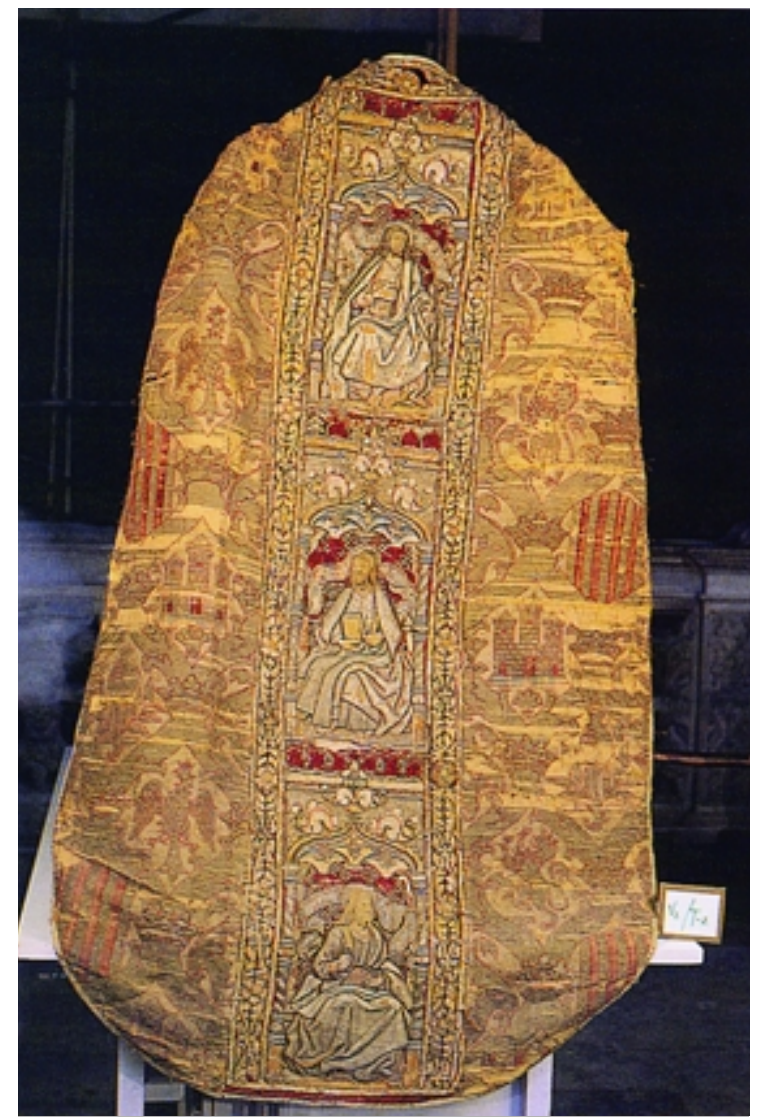

vecha la composición técnica de dicho galón, a modo de pequeñas anillas en el borde, para pasar el hilo que realiza el punto de unión con el resto de la casulla.

\section{Estado de conservación}

El estado de conservación de la pieza a su llegada a las instalaciones del IAPH se podía considerar como muy deficiente presentando un gran número de importantes alteraciones localizadas en puntos vitales de la misma, fundamentalmente en la zona de los hombros y en el pectoral (foto $n^{\circ} 3$ ).
Estas alteraciones han sido consecuencia directa de una serie de agentes de deterioro generalmente externos a la propia obra, tales como: suciedad superficial, medioambiente, uso frecuente que ha sufrido la pieza hasta hace pocos años en determinadas épocas del año, manipulación inadecuada, intervenciones anteriores y sistema expositivo, al igual que derivados de la propia naturaleza y constitución de la pieza, entre los que destacamos envejecimiento natural de la fibra y perdida de elasticidad.

La casulla presentaba múltiples intervenciones realizadas con criterios, técnicas y materiales poco idóneas. Los datos de que disponemos no nos permiten precisar la época en que fueron realizadas, pero sí podemos determinar la localización y naturaleza de los materiales empleados, así como las alteraciones por ellos provocadas, como veremos a continuación:

- Aplicación de un forro de algodón de color ocre claro a toda la superficie de la casulla por su reverso, de dimensiones más reducidas. En concreto se han detectado tres centímetros de diferencia en todo el perímetro de ambas piezas, dando lugar a la aparición de tensiones locales y de deformaciones importantes en las piezas originales.

- Remate de todo el perímetro de la casulla con un galón de color verde-amarillento realizado en seda e hilo metálico dorado que une todo el conjunto.

- Se han encontrado 40 parches de materiales y colores diversos en el interior del cuerpo de la casulla,a fin de resanar las lagunas y desgastes existentes. Por lo general son de mayor dimensión que la pérdida correspondiente. En concreto se tratan de 5 parches de seda amarilla tejidos con técnica de damasco, 25 de lana del mismo color, 9 de lino de color crudo, ambos en técnica de tafetán y I de la misma pieza de la casulla que corresponde al lateral izquierdo del anverso del cuerpo. Estas piezas están fijadas de cualquier manera con hilos de diferentes colores a los cuerpos, siendo éstos visible por su anverso ( foto $n^{\circ} 4$ ).

- Realización de múltiples zurcidos y fijación por hilos con objeto de unir rajas, rotos, desgarros, elementos sueltos y costuras abiertas. En el cuerpo se han detectado diversos colores: hilos amarillos y rojos, que desteñían en presencia de humedad, e hilos de color crudo de algodón más fuertes que el tejido de base original. Se localizan en un porcentaje más elevado en la parte superior de los hombros de ambos cuerpos. Como ya se ha comentado es la zona más deteriorada y por tanto la más intervenida. En el orfre encontramos otro tipo de hilo de color rosa en algodón muy fuerte.

La mayoría de estos cosidos y adiciones han provocados desgarros y rotos puntuales en zonas adyacentes a las alteraciones que pretendían subsanar, debido fundamentalmente a la fortaleza del material seleccionado en esta operación. En la mayoría de los casos al ofrecer mayor resistencia que el original termina por romperlo. 


\section{Principales alteraciones}

Con independencia de las ya comentadas derivadas de las intervenciones anteriores que ha sufrido la casulla, se ha detectado una fuerte acumulación generalizada de polvo y suciedad por toda su superficie. Las más importantes las describimos a continuación:

Lagunas. Quizá la más significativa de la alteraciones presentes era el gran número de lagunas existentes tanto en el soporte como en la decoración (foto $n^{\circ}$ 5). La morfología, tamaño y localización es muy variada en el conjunto de la pieza. En el cuerpo las de mayor dimensión se localizan en la parte superior de los hombros y corresponden a pérdidas de hilos metálicos y del soporte, mientras en el orfre las más evidentes son la pérdida de las lentejuelas y del matizado en hilo de seda.

En general corresponden a un solo estrato o a varios según las zonas. En función del nivel en el que se manifiesta se han detectado 5 tipologías diversas, dos en el cuerpo y tres en el orfre:

- Los cuerpos laterales presentan lagunas en profundidad que corresponde a la pérdida del soporte, es decir, desaparición total del tejido base o del terciopelo labrado, y otra superficial que agrupa a las múltiples pérdidas del hilo metálico existentes.

- Respecto al orfre se detectan tres tipos de lagunas: pérdidas de soportes totales que nos dejan ver el forro de base que protege toda la cenefa de la decoración, desaparición de numerosas lentejuelas, fundamentalmente porque al ser los elementos más superficiales están más expuestos al roce, y por último, la pérdida del matizado en seda tanto de las carnaciones de los personajes como de las lentejuelas.

En el forro aparece una sola tipología de lagunas correspondiente a pérdidas del tejido de tafetán de base.

Rotos y desgarros. Aparece esta alteración de forma generalizada por toda la superficie de la casulla, si bien se hace más patente en la parte anterior de los hombros. En general son consecuencia de la manipulación inadecuada de la pieza, de enganches y de roces provocados por el uso. Se localizan principalmente en las zona de los brazos a la altura del pecho y de los hombros, concretamente son más numerosos en el lateral derecho. En el orfre sólo encontramos rotos localizados concretamente en la zona del cuello, que es, en este sentido, el área más castigada por el uso.

Los rotos y desgarros de forma inmediata originan lagunas, de aquí la importancia de su pronto tratamiento.

Las dimensiones de los desgarros son en general de tamaño reducido, con la excepción de aquellos que se localizan en la parte anterior derecha del cuerpo y que abarcan casi el ancho total de ambos laterales, concretamente $19 \mathrm{~cm}$.
Desgastes. El carácter de vestimenta litúrgica, conlleva necesariamente a utilizarla como objeto cultural, al menos de forma ocasional. Este hecho contribuye en gran medida a su degradación. En este caso concreto, la casulla ha sido empleada como vestimenta por los capellanes reales en determinadas fechas históricas hasta hace relativamente pocos años.

Los desgastes son muy abundantes en la obra. Se manifiestan bajo dos formas diferentes según la profundidad en la que se localizan. La primera corresponde al desgaste de las zonas más superficiales y delicadas cuya materia es la seda. En concreto nos referimos tanto al pelo del terciopelo rojo de los cuerpos, el cual se ha perdido casi por completo en todos los contornos de los motivos heráldicos, siendo más evidente en aquellas zonas donde la concentración de terciopelo era mayor, como ocurre con las barras y los castillos-, como a los desgastes de los hilos de seda que crea y matiza las carnaciones, las lentejuelas de los personajes y los motivos decorativos del orfre.

El segundo tipo se presenta en las zonas interiores del relleno del orfre, el cual se ha quedado al descubierto tras perder las lentejuelas que los protegían. Este tipo de alteración se corresponde con los mismas áreas donde existen lagunas de lentejuelas en el orfre.
5 Detalle de hilos metálicos sueltos en el cuerpo.

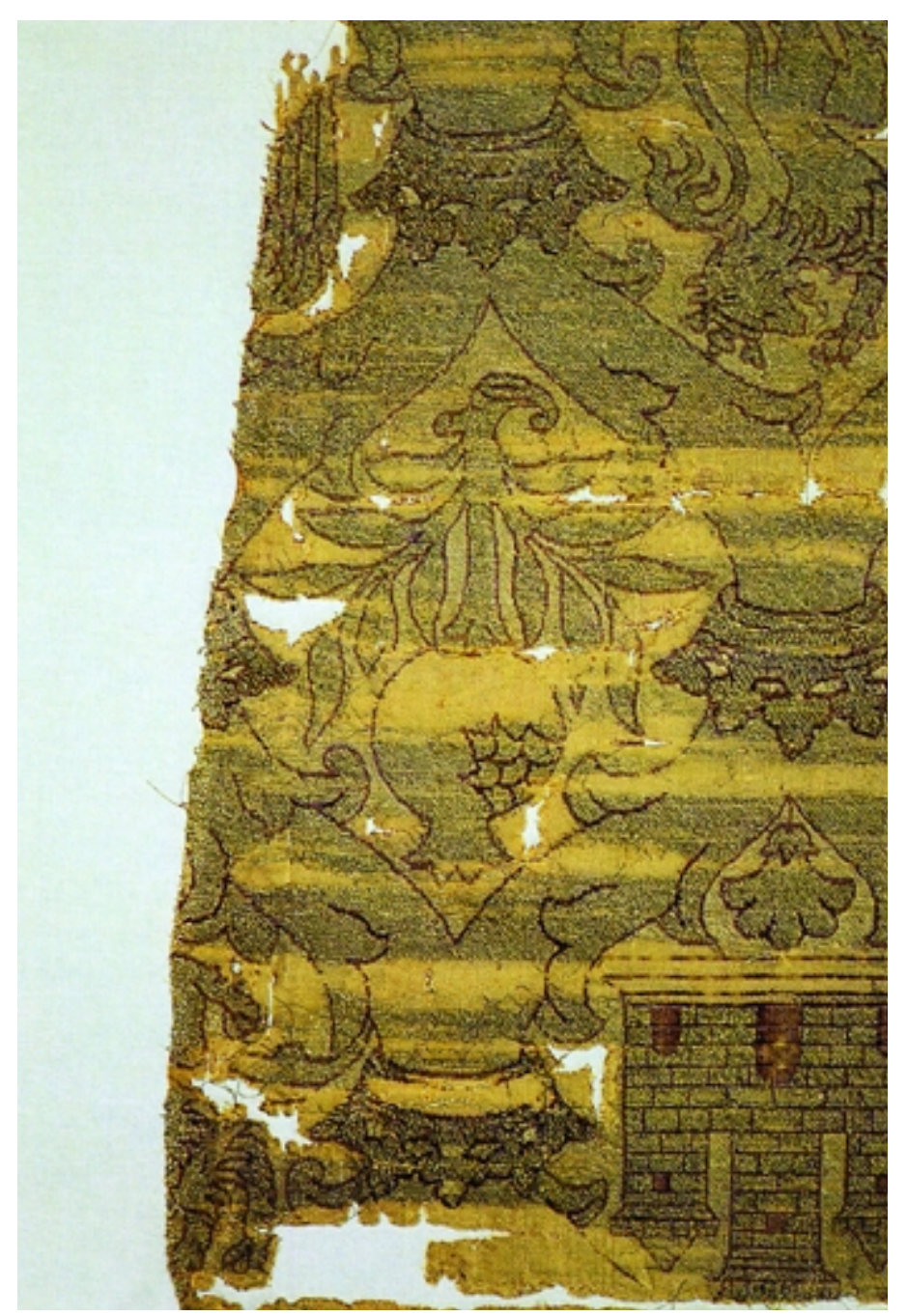


Deformaciones. Otra de las alteraciones detectadas son las numerosas deformaciones que presentaba la obra tras el desmontaje de la percha en la que ha estado expuesta. Si bien esta alteración se presenta de forma generalizada se caracteriza en esta pieza por manifestarse bajo diferentes tipologías, en función de las causas que las han originado, destacando las siguientes:

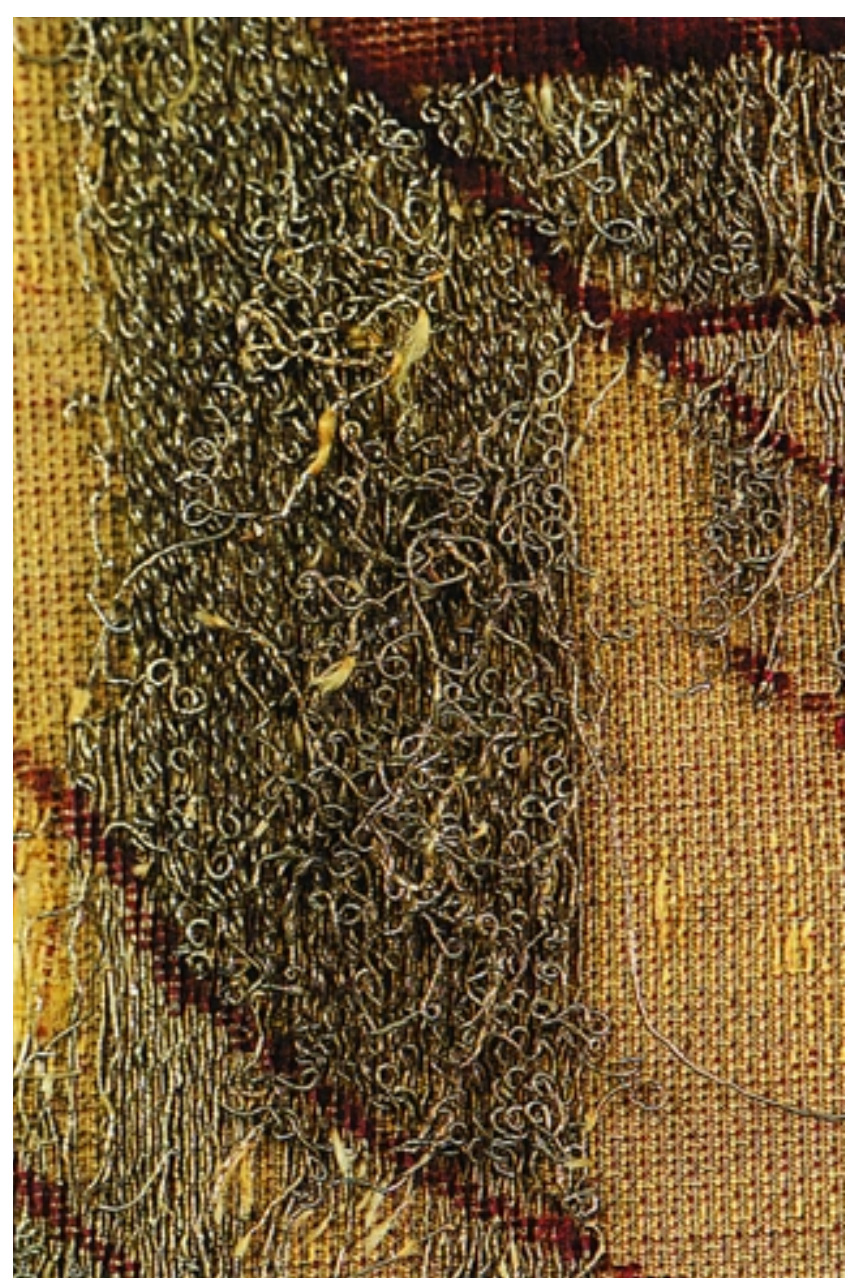

6. Detalle de hilos metálicos sueltos en el cuerpo.

- Deformaciones derivadas del estiramiento de la fibra original por pérdida de elasticidad, fundamentalmente en la zona de los hombros, dando lugar en algunos casos al adelgazamiento de la fibra, y de consecuencia, a su rotura.

- Plegamientos tanto en el sentido vertical como en el horizontal provocados por el sistema expositivo. Tensiones y encogimientos como consecuencia de la adaptación del tejido original a los parches subyacentes a los que se mantenía sujeto, y por último,

- Abolsados localizados en todo el perímetro de la casulla como consecuencia de la adaptación del forro que le sirve de base.

Pérdida de fijación de elementos constitutivos. Esta alteración se manifiesta bajo dos formas diferentes.
En primer lugar los descosidos, muy abundantes por toda la superficie de la obra aunque no llegan a tener grandes dimensiones. En el orfre se advierten la separación de algunas de las piezas de la decoración de los personajes y fundamentalmente de las costuras de la retorcha, producida por la pérdida del hilo que mantiene la unión entre diferentes piezas.

En segundo lugar los hilos sueltos, alteración muy numerosa y significativa de la obra. El mayor porcentaje corresponde a los hilos metálicos que se encuentran en ambos cuerpos (foto $n^{\circ} 6$ ). Las causas la encontramos en el hecho de que al ir en superficie fijados sólo por una urdimbre de ligadura de seda, es mucho más fácil que se produzca su rotura como consecuencia de estar más expuesto a los roces, al desgaste del hilo de seda y a las manipulaciones.

Alteraciones cromáticas. Se advierte una cierta pérdida homogénea del colorido original de la casulla producida principalmente por los efectos que la luz (natural y artificial) ha causado en la casulla a través del tiempo. La exposición prolongada en el interior de una vitrina dotada de sistema de iluminación incandescente que proporcionaban una elevada potencia calorífica y alto porcentaje de infrarrojos, unido al hecho de que en el interior del Museo incidía la luz solar, ha contribuido a provocar o acelerar la decoloración de los tintes y colorantes empleados y a degradar la fibra de los soportes textiles.

Alteraciones de los complementos decorativos. Se limita esta alteración casi exclusivamente a las lentejuelas las cuales se ven afectadas por desgastes, roturas, deformaciones, pérdida del hilo de seda que las mantiene sujeta al soporte y oxidación de la plata cuando quedan en contacto con el aire por perdida del oro que las recubre.

\section{Estudio analítico}

Este estudio analítico ha tenido por objeto básicamente la identificación de los principales materiales constitutivos de la casulla, así como la determinación de sus características y comportamiento. Para ello se han extraído muestras de la pieza en puntos no estratégicos de la misma, y siempre en lugares donde existía alguna alteración.

Los resultados de esta investigación han aportado datos significativos sobre los materiales constitutivos (naturaleza, composición, características técnicas y mecánicas), sobre la solidez y firmeza del color; de interés para la correcta aplicación de determinados tratamiento, al igual que para la determinación de la época de uso de algunos de los tintes empleados que han contribuido al estudio histórico de la pieza.

El estudio analítico de la obra ha constado fundamentalmente en dos partes. 


\section{Caracterización del tejido:}

- Identificación de las fibras textiles empleadas por medio de la microscopía óptica de la sección transversal y longitudinal de las mismas y con ensayos microquímicos con reactivos específicos.

- Identificación de la estructura de los hilos y otros elementos metálicos, por microscopía electrónica de barrido con microsonda de Rayos X (SEM-EDX), y

- Determinación cuantitativa de la composición de dichos elementos por Fluorescencia de Rayos $X$.

Análisis de colorantes por cromatografía líquida de alta resolución (HPLC) combinada con análisis por espectroscopía ultravioleta mediante detector de matriz de diodos.

Se han tomado 27 muestras intentando cubrir los distintos materiales y zonas de la pieza, que se han analizado por las distintas técnicas anteriormente mencionadas. Los resultados obtenidos los exponemos a continuación:

Las fibras empleadas varían en función de la utilización del tejido. Para el forro se ha utilizado tejido de algodón, salvo en los añadidos que presenta esta pieza que son de lino. El cuerpo es de seda. Los relieves de la decoración del orfre se han conseguido superponiendo tres estratos de diferentes tejidos, el inferior de seda, el intermedio de lana y el superior de lino.

Los hilos metálicos están formados por un alma de seda y una lámina de plata aleada en distintas proporciones con cobre y chapada en oro (foto $n^{\circ} 7$ ). Las muestras analizadas podrían englobarse dentro de dos grupos con diferente composición de la aleación.

\begin{tabular}{cc} 
Tipo I & Tipo II \\
\hline Plata $68-75 \%$ & Plata c.a. $85 \%$ \\
\hline Cobre $21-28 \%$ & Cobre c.a. $11 \%$ \\
\hline Oro c.a. $2 \%$ & Oro c.a. $2,5 \%$ \\
\hline
\end{tabular}

Las lentejuelas están compuestas también por una aleación de cobre y plata, en proporciones del 5 y $79 \%$ respectivamente, doradas con una mayor cantidad de oro, 15\% aproximadamente.

Los colorantes utilizados son los siguientes:

\begin{tabular}{ll}
\hline Amarillos & Gualda y zumaque veneciano \\
\hline Azul & Índigo \\
\hline Negro & Ácido gálico \\
\hline Rojo & Kermes y cochinilla americana \\
\hline Rosa & Palo brasil \\
\hline Verde & Gualda+índigo \\
\hline
\end{tabular}

El zumaque veneciano, solo o mezclado con gualda, se usa para los hilos amarillos chapados con metal y la gualda sola para los hilos amarillos descubiertos.
La cochinilla americana es un colorante utilizado con posterioridad al descubrimiento de América, a partir del siglo XVI, y se ha encontrado en muestras de terciopelo rojo utilizado en el orfre.

\section{Tratamiento realizado}

Los criterios seleccionados en la intervención de la casulla han estado condicionados por el grado de degradación, así como por la importancia de las alteraciones que presentaba, tanto en diversidad, como en localización y dimensión. Estos factores nos han inducido a abordar la actuación desde la perspectiva meramente conservativa, es decir, eliminando al máximo los deterioros existentes, y recuperando la lectura integral de la pieza sin recurrir en ningún momento a la reconstrucción parcial o total. Para ello se ha empleado una metodología de trabajo que parte de los resultados de los estudios preliminares efectuados sobre la pieza (históricos, analíticos, características técnicas y diagnóstico) con objeto de aplicar única y exclusivamente los tratamientos mínimos y necesarios que requiere la pieza para devolverle la integridad y unidad perdida.

El estado de conservación y el proceso de intervención ha sido documentado tanto gráfica como fotográficamente con distintas técnicas (macro y micro fotografías, luz rasante, iluminación normal).

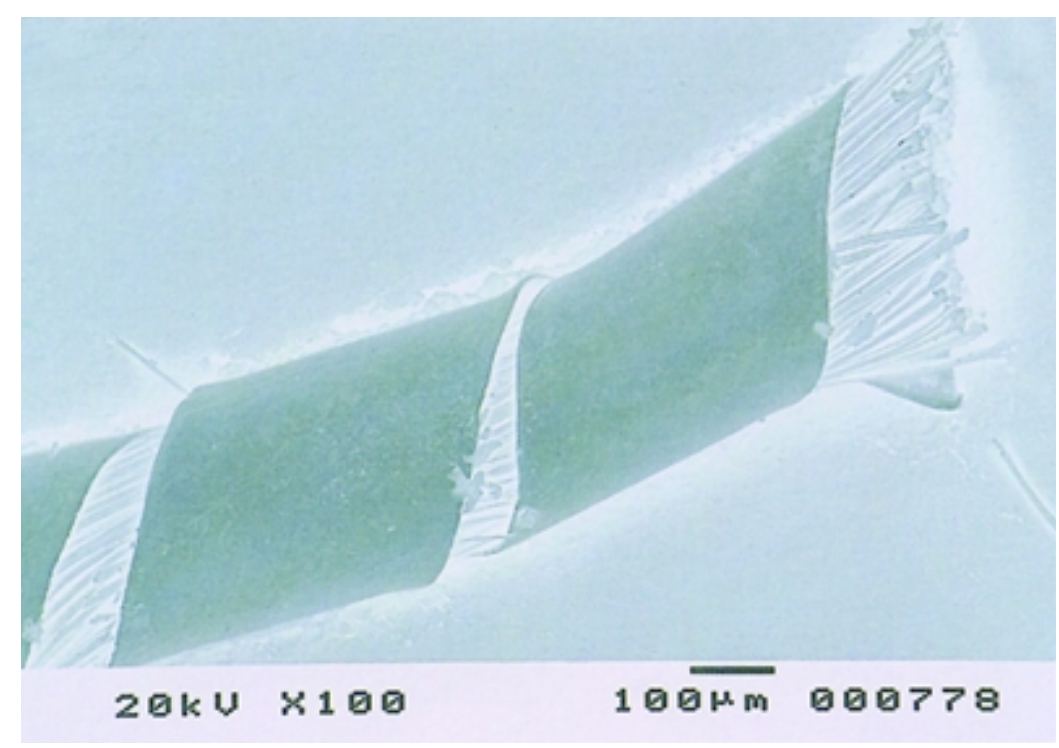

En la aplicación de los diferentes tratamientos se han empleado materiales, inocuos e inalterables que garantizan la estabilidad y duración de la intervención sin consecuencias negativas para el original y tratamientos que permiten la reversibilidad de la actuación en caso necesario.

7. Observación al microscopio electrónico de una de las muestras de hilos metálicos, puede apreciarse su estructura, y además, como en algunas zonas (áreas más oscuras) el dorado está desapareciendo y queda al descubierto la plata.

La intervención se inició con la eliminación de la suciedad superficial que presentaba la totalidad de la casulla mediante microaspiración ayudándose de brochas y pinceles suaves e interponiendo una gasa de protección. 


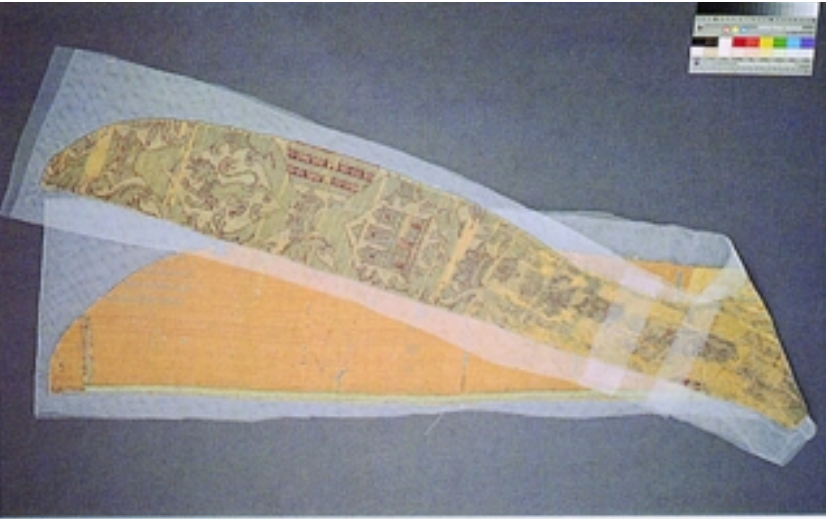

8. Protección con tul del cuerpo derecho como medida preliminar al proceso de lavado.

9. Proceso de lavado

Con objeto de poder aplicar determinados tratamientos, y teniendo en cuenta que en este caso concreto, las costuras no eran las originales, se procedió a separar las diferentes partes constitutivas que componen la casulla: galón, orfre, cuerpos y forro, y a realizar patrones de las mismas, indispensables en el correcto montaje final de la obra.

Posteriormente se eliminaron las restauraciones existentes de antiguas fijaciones y consolidaciones del soporte del cuerpo y del orfre, que como hemos visto estaban realizadas con materiales inadecuados que afectaban a la integridad del original (parches, zurcidos, fijación de hilos, etc).

Concluidas estas actuaciones se inició el proceso de limpieza de la casulla. Las características técnicas de la obra no ha permitido efectuar el mismo método en las diferentes partes constitutivas, optándose por realizar un lavado en húmedo de ambos cuerpos, forro y galón, mientras que para el orfre se eligió una limpieza en seco con disolventes. El motivo de esta decisión se basa fundamentalmente en las características intrínsecas del orfre, fundamentalmente en el elevado número de estratos que configura su decoración y en la diversidad de materiales que intervienen en su estructura (relleno y ornamentación) cuyo comportamiento durante el secado, provocaría dis-

10. Selección de los soportes e hilos de seda en base a su naturaleza y cromatismo.

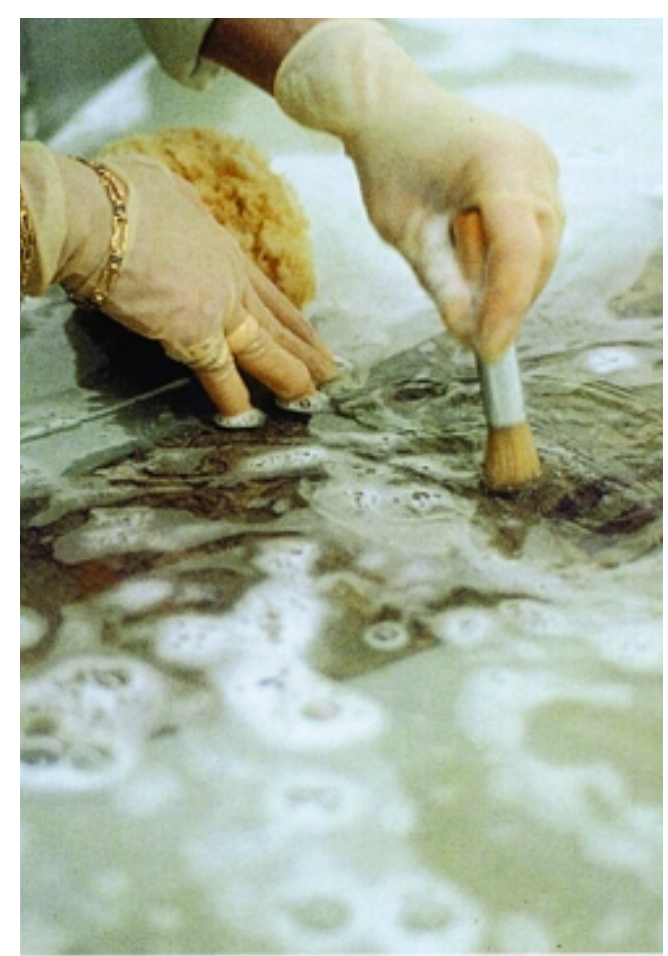

Como medida preliminar se protegieron con tules aquellas partes que como los cuerpos y el galón presentaban riesgos de perdidas de elementos durante el proceso del lavado (foto $n^{\circ}$ 8). La limpieza del galón, cuerpos y forro se efectuó en plano y por separado en una cuba de lavado con agua desmineralizada y desionizada y detergente neutro (Lisapol en proporción de $0.07 \mathrm{gr} \times$ litro de agua), enjuagándose las veces que fueron necesaria hasta la eliminación total del detergente empleado (foto $n^{\circ}$ 9).

La limpieza del orfre se llevó a cabo en seco con disolvente (tricloroetileno) y papel absorbente, salvo las lentejuelas que se limpiaron con un hisopo humedecido en agua desmineralizada y alcohol al 5\%.

Con objeto de ordenar las tramas y urdimbres y eliminar con ello todas las deformaciones, se procedió a la alineación de las piezas lavadas en húmedo, una a una, en una mesa de secado sobre la que se dispusieron los patrones y se alinearon las piezas fijando las partes dañadas y los perímetros con alfileres de entomología. El secado se efectuó al aire sin necesidad de medios auxiliares.

Una vez lavada, seca y corregida las deformaciones se procedió a la selección de los soportes (algodón 100\% y crepelinas de seda 100\%) e hilos (seda natural de 4 cabos), a su lavado y desaprestado, a su tinción con tintes sintéticos (Ciba Geigy), y a su posterior alineación siguiendo el mismo método que para las partes originales. Todas estas operaciones previas nos permitieron disponer de los materiales necesarios para efectuar la posterior consolidación de las diferentes piezas constitutivas.

La consolidación de las piezas se realizó reforzando su reverso con los soportes seleccionados, en base a su 
resistencia y a su cromatismo, mediante líneas de fijación con hilo de algodón y punto de bastilla simple (foto $\left.n^{\circ} 10\right)$.

Tras esta operación se efectuó la fijación de todos los elementos sueltos o desprendidos existentes en su estructura o superficie, es decir, hilos sueltos (metálicos o de seda) y lentejuelas, así como de los bordes de lagunas, desgarros, etc. La fijación se realizó con hilo de seda del matiz más aproximado posible al original previa ordenación de los distintos elementos (foto $n^{\circ} \mid \mathrm{I}$ ). Las lagunas se matizaron previamente con crepelinas de seda de la tonalidad adecuada para obtener la integridad cromática en el conjunto de la pieza, y se fijaron mediante punto de restauración (foto $n^{\circ} 12$ ) y de escapulario (foto $n^{\circ} 13$ ) según los casos (foto $n^{\circ} \mid 4$ ).

Una vez finalizada la fijación se procedió al montaje final de las distintas piezas integrantes de la misma realizándose en tres fases: cuerpos y orfre, forro y galón.

En la unión de los cuerpos al orfre el método seguido para la intervención fue la costura, empleándose para ello un punto de bastilla muy cerrado excepto en la zona superior de los hombros donde se llevó a cabo un punto de pespunte, más fuerte que el anterior y que confería mayor consistencia.

El hilo utilizado para estas costuras debía tener gran resistencia ya que su finalidad era mantener la unión de las costuras, por lo que se eligió una mezcla de algodón y acrílico. Tras el montaje de estas piezas los cuerpos se reforzaron con una tela de algodón que hacía las veces de entretela, fijándose a un $\mathrm{cm}$. de distancia del orfre mediante un punto de bastilla.

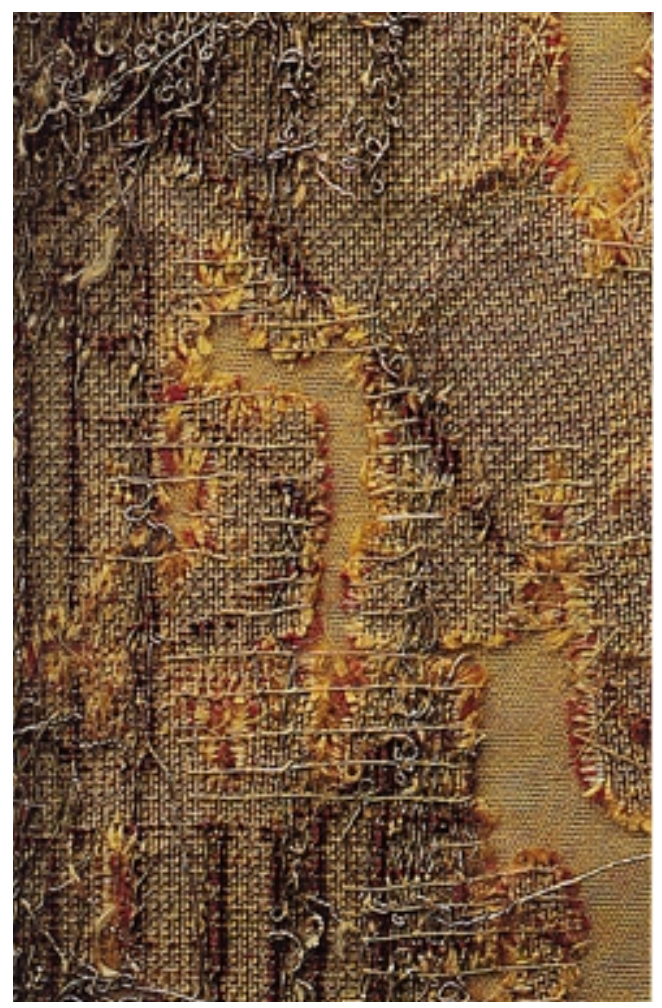

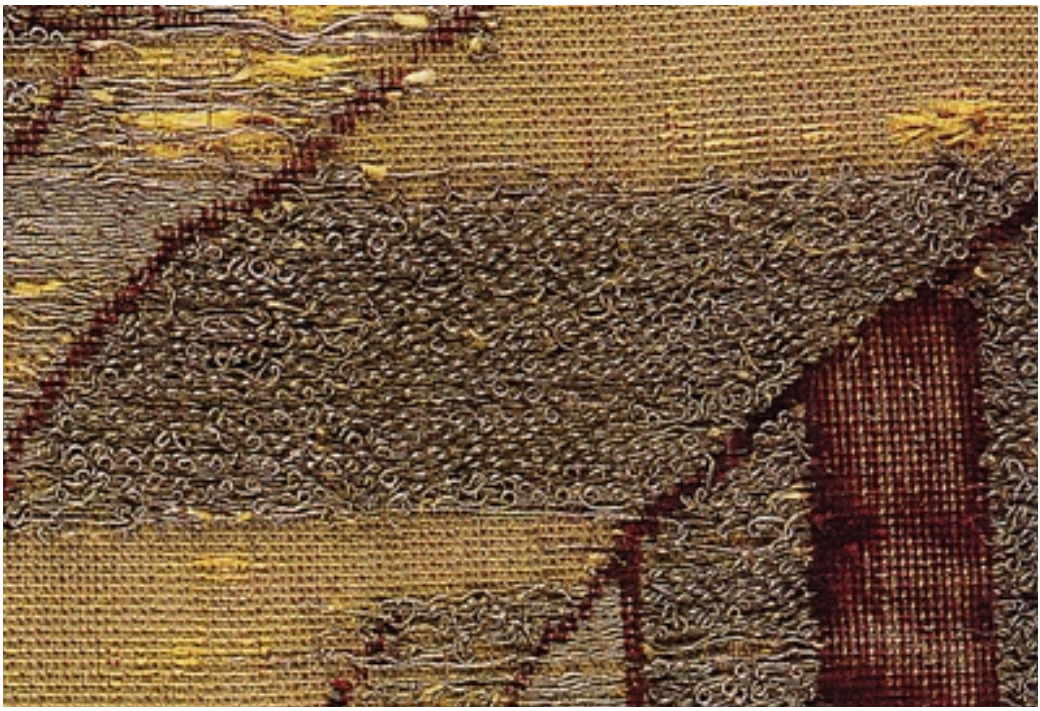

El montaje del forro y la adaptación a la obra fue una de las tareas más difíciles de este proceso debido a que el forro era tres $\mathrm{cm}$. más pequeño que la casulla en todo su perímetro. La forma de conservarlo y adaptarlo perfectamente a la misma se consiguió añadiendo una nueva pieza en la zona del cuello la cual fue fijada mediante costura.

La fijación del forro al resto del conjunto se llevó a cabo mediante un punto de bastilla simple a $\mathrm{I} \mathrm{cm}$. del borde del orfre con hilo de algodón de color similar al original.

Por último se montó el galón en todo el perímetro de la casulla mediante un punto de pespunte e hilo de algodón, manteniendo de este modo unidas a todas las piezas integrantes que componen la obra (foto $n^{\circ} \mid 5$ ).

\section{Sistema expositivo}

\section{Antecedente}

La casulla en el antiguo montaje expositivo del Museo de la Capilla Real de Granada se encontraba en el interior de una vitrina de madera conjuntamente con otras piezas textiles, en concreto un frontal de altar, un dosel o altar de campaña y dos dalmáticas pertenecientes, como la casulla, al terno del rey Fernando el Católico. Además en su interior se encontraban expuestas diversas piezas de orfebrería entre la que des-

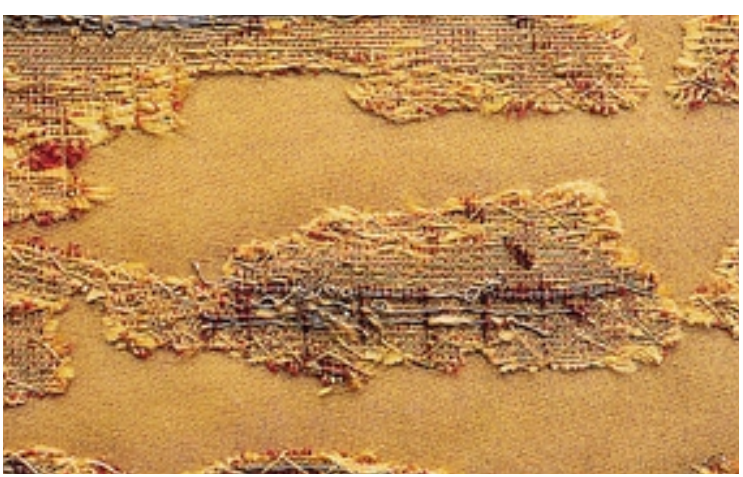

12. Fijación de lagunas en el cuerpo mediante punto de restauración.

13. Fijación de lagunas en el cuerpo mediante punto de escapulario. 
$\frac{\nwarrow}{\infty}$
$\sum_{\square}$
$\sum$

14. Detalle del tratamiento de lagunas tras la intervención.

15. Vista general del reverso de la casulla concluida la intervención
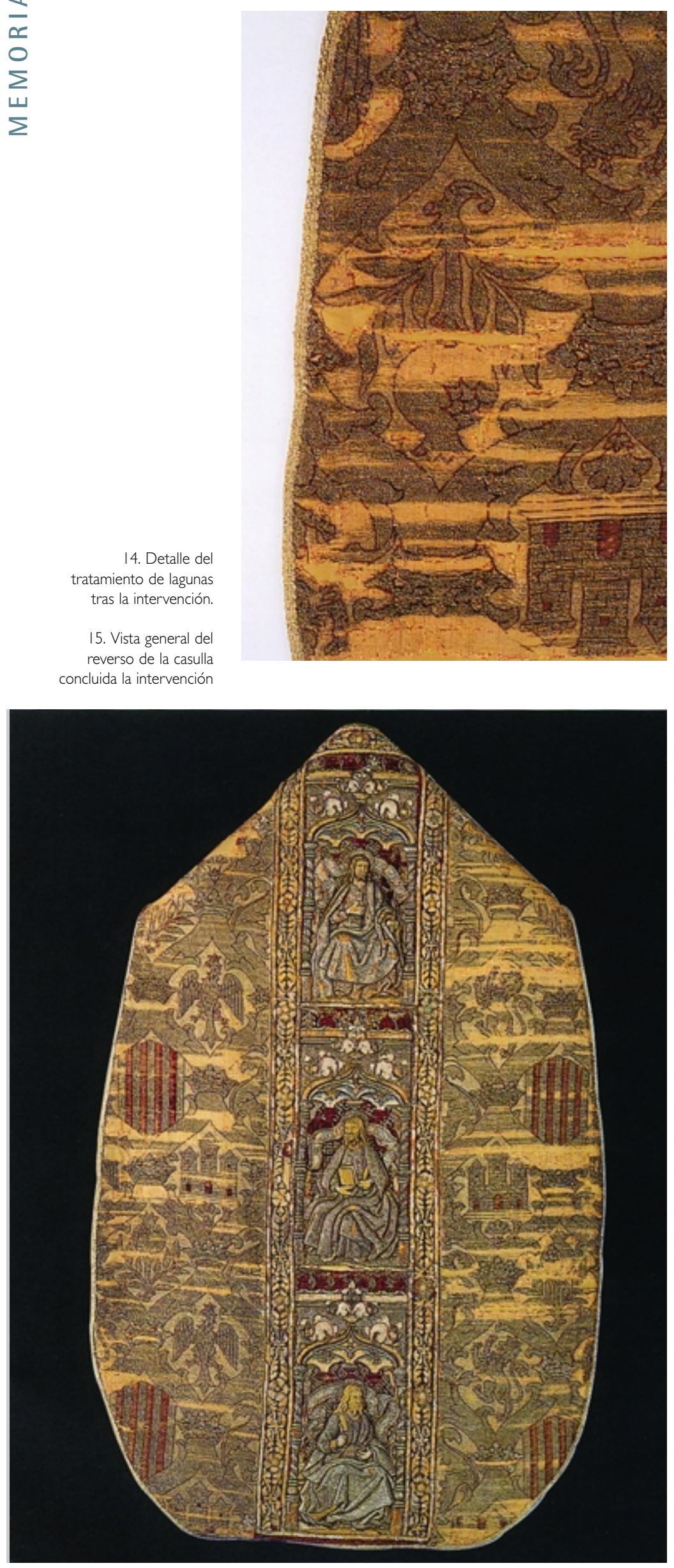

tacaba el espejo de la reina Isabel la Católica. El espacio de la vitrina no era suficiente para exponer todo este material, de tal forma, que para aprovecharlo mejor las piezas de este terno se encontraban depositadas sobre una percha de uso doméstico colocada sobre un trípode, de altura no superior al metro y medio, y plegada por su base, con objeto de que el espectador pudiese ver las restantes piezas (foto $n^{\circ}$ 16).

A este montaje expositivo se unía el hecho del tipo y ubicación de la iluminación empleada, consistente en 12 tubos incandescente de 40 watios cada uno, colocados internamente en ambos laterales y en su frontal. Todos ello contribuía a crear un ambiente considerado no idóneo desde el punto de vista conservativo y museográfico.

Con objeto de estudiar el ambiente del interior del Museo y de las vitrinas que en él se encontraban, se instaló una pequeña central microclimática de 8 canales que ha permitido adquirir y grabar los parámetros microambientales (temperatura $(T)$ y humedad relativa $(\mathrm{Hr}))$. Las sondas se colocaron tanto en el exterior como en el interior del Museo y de la vitrina.

Las conclusiones ambientales del estudio del antiguo Museo de la Capilla Real han permitido definir tres situaciones diferentes:

- No existe una interferencia directa del exterior en el interior del Museo. Sí se ha detectado cómo la apertura y clausura de la sala al público incide en la evolución ambiental interna.

- El comportamiento térmico de la sala es análogo al del interior de la vitrina, pero en la vitrina el salto térmico es notablemente superior. Este hecho implica un gran estrés físico para los objetos en ella contenidos. Este aumento se explica por el sistema de iluminación adoptado.

- Se ha detectado un comportamiento inestable en el contenido de vapor en el interior de la vitrina en relación con los niveles existentes en la sala, condicionado por el horario de apertura-clausura. Cuando la vitrina está encendida se observa un aumento de vapor considerablemente superior al de la sala, mientras que cuando se apaga, desciende a niveles inferiores del resto del Museo.

Este comportamiento climático es extremadamente dañino para la conservación de materiales higroscópicos como los tejidos, ya que la contínua dilatacióncontracción de las fibras los deteriora fácilmente.

\section{Nuevo montaje expositivo}

Centrándonos únicamente en el diseño y características del nuevo montaje expositivo de los tejidos del Museo de la Capilla Real, y en concreto de la casulla, tenemos que decir que gracias a los estudios preliminares efectuados por el equipo de especialistas que ha intervenido en este trabajo y al seguimiento realizado 


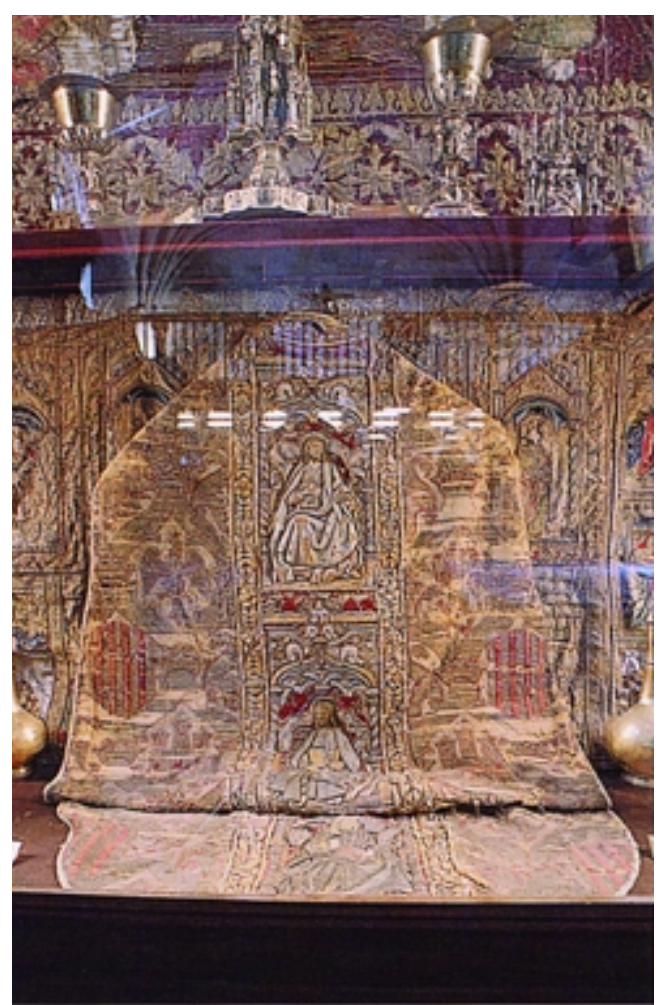

por el IAPH, se ha podido hacer compatible con la conservación de la piezas expuestas, la exposición al público de la colección de tejido de la Capilla Real.

Los tejidos se encuentran expuestos en el interior de una vitrina de madera que reúne las siguientes características (foto $n^{\circ} 17$ ):

- La vitrina está constituida por dos compartimentos diferentes, el primero de ellos que sirve de expositor de las piezas expuestas y el segundo dotado de unos cajones debidamente calibrados en función del volumen de la vitrina para contener el gel de sílice necesario para asegurar la estabilidad climática interior, en aquellos casos que sea necesario intervenir con un material tampón. Ambos compartimentos se comunican entre sí y están aislado del exterior.

- Las dimensiones de la vitrina han sido estudiadas en relación directa con el volumen de las piezas expuestas y con el tipo de montaje expositivo seleccionado para las mismas (perchas adecuadas a su morfología).

- La vitrina es completamente estanca. Este hecho garantiza la no penetración de polvo y de los agentes contaminantes, al mismo tiempo que contribuye a mantener un microclima fácil de controlar.

- Fácil acceso desde el exterior para facilitar el mantenimiento.

- Para esta vitrina se ha estudiado un sistema de iluminación innovativo en el campo de la conservación denominado "guía de luz". Las ventajas de este nuevo sistema respecto a los tradicionales son las siguientes: se obtiene una alta eficiencia luminosa sin emisión de radiaciones consideradas nocivas (infrarrojas y ultravioletas), no emite calor que podría desestabilizar el equilibrio microclimático de la vitrina ya que la fuente luminosa está colocada en su exterior. Además, no altera el cromatismo de las piezas expuestas ya que emite una luz cromáticamente considerada ideal para poder apreciar los tonos cálidos y fríos sin distorsión (temperatura de color de 3.150 grados kelvin).

Para iluminar la vitrina se han utilizado dos guías de luz empleándose como fuente luminosa cuatro lámparas dicróicas de 50 watios y 12 voltios cada una

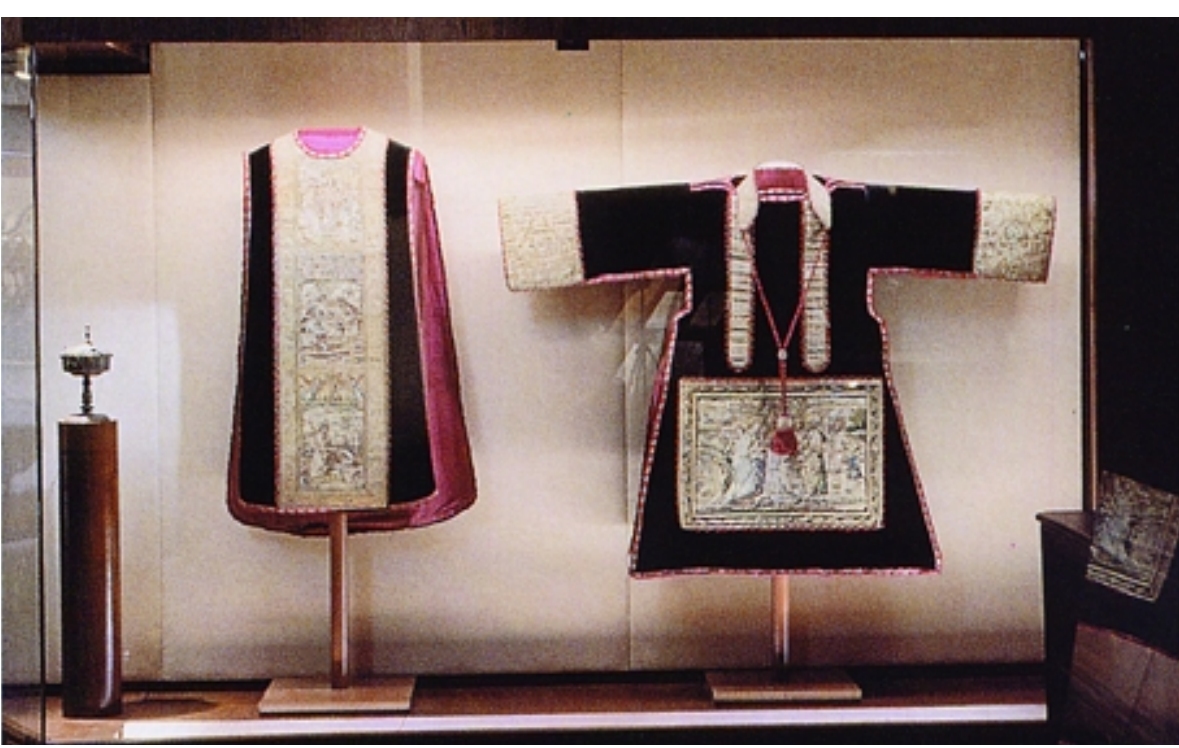

de ellas. Con este sistema de iluminación se ha logrado una iluminación uniforme en su interior que no supera los 100 lux.

En cuanto al sistema expositivo seleccionada para esta pieza tenemos que decir que reúne las características técnicas necesarias para hacer compatible su presentación con su conservación. La pieza se expone en vertical sobre una percha de madera que reúne las siguientes condiciones:

- Brazos de forma redondeada (media circunferencia de unos diez a quince $\mathrm{cm}$. de diámetro) que aporta una amplia superficie de apoyo para los hombros y a su vez son articulables con el fin de obtener la inclinación de hombros exacta y conseguir la perfecta adaptación a su morfología.

- Dotada de una barra extensible que permite graduar la altura hasta lograr la adecuada.

- Equipada con un soporte separador en la parte inferior para mantener los extremos de la pieza abiertos y evitar que los cuerpos se plieguen hacia el interior, tanto por su anverso como por su reverso.

La parte superior de la percha sobre la que descansará el peso de la casulla, es decir los brazos, está conve-
16. Detalle de la casulla en el anterior montaje museográfico.

17. Vista general de la vitrina donde irá ubicada la casulla en el Museo de la Capilla Real. 
nientemente forrada con muletón de algodón para amortiguar los ángulos, rellenar huecos y repartir de forma uniforme el peso de a fin de evitar que éste no recaiga sobre un punto específico de la pieza y prevenir alteraciones en ella.

\section{Conclusiones}

Con esta intervención el IAPH ha abierto una línea metodológica de investigación e intervención en el Patrimonio Textil Andaluz, al tratarse de la primera actuación que se ha llevado a cabo siguiendo los actuales criterios en la especialidad de conservación-restauración de Tejido sobre una pieza textil de la importancia y complejidad técnica y de tratamiento, como es la casulla del terno blanco chapado del rey Fernando el Católico.

Los estudios preliminares realizados anterior a la propia intervención (histórico, analítico, técnico, ambientales, etc), así como la nueva instalación museográfica del Museo de la Capilla Real de Granada, acción coordinada por este Instituto, han permitido que desde el IAPH se desarrolle la actuación y la aplicación de los tratamientos que necesitaba la pieza con la máxima profesionalidad y garantías, al igual que asegurar su conservación temporal en un montaje expositivo afín a sus características morfológicas y técnicas.

\section{Equipo de trabajo IAPH}

Dirección de la intervención: $M^{a}$ José González López. Jefe del Dpto. Tratamiento. Centro de Intervención del IAPH.

Estudios histórico-artístico: Gabriel Ferreras Romero. Historiador del Arte. Dpto. de Investigación, Centro de Intervención del IAPH.

Análisis de fibras: Lourdes Martín García. Química. Dpto. de Análisis. Centro de Intervención del IAPH.
Intervención de conservación-restauración: Araceli Montero Moreno y Carmen Ángel Gómez. Restauradoras. Dpto. Tratamiento. Centro de Intervención del $\mathrm{IAPH}$.

Fotografía: Eugenio Fernández Ruiz. Fotógrafo. Dpto. de Análisis. Centro de Intervención del IAPH.

Sistema expositivo e iluminación: Raniero Baglioni. Sector Conservación Preventiva. Centro de Intervención del IAPH.

\section{Agradecimientos}

Nuestro particular agradecimiento a los especialistas y a las Instituciones que han colaborado en el desarrollo de los estudios, investigaciones e intervenciones realizadas en esta pieza, y gracias a su dedicación y esfuerzo hoy día podemos mostrar el resultado de este trabajo.

Asesoramiento técnico en conservación-restauración: $M^{a}$ del Socorro Mantilla de los Ríos.

Identificación de colorantes y elementos metálicos: Enrique Parra y Ma Dolores Gallo. Laboratorio de Química del ICRBC. Madrid

La caracterización al microscopio electrónico de las fibras metálicas se ha efectuado en el Instituto de Ciencia de Materiales (Universidad de Sevilla- CSIC).
Estudio ambiental y de luminotecnía: Carlos Cacace y Fabio Aramini. Laboratorio de Física del ICR. Roma

Diseño del nuevo montaje museográfico de la Capilla Real: Pedro Salmerón Escobar.

Suministros de tintes y colorantes: Ciba -Geigy. Barcelona. 